\title{
A Microfluidic Atmospheric-Pressure Plasma Reactor for Water Treatment
}

\author{
Laila Patinglag $^{1} \cdot$ David Sawtell $^{1} \cdot$ Alex Ies $^{2} \cdot$ Louise M. Melling $^{1} \cdot$ Kirsty J. Shaw $^{1}$
}

Received: 19 November 2018 / Accepted: 4 March 2019 / Published online: 20 March 2019

(c) The Author(s) 2019

\begin{abstract}
A dielectric barrier discharge microfluidic plasma reactor, operated at atmospheric pressure, was studied for its potential to treat organic contaminants in water. Microfluidic technology represents a compelling approach for plasma-based water treatment due to inherent characteristics such as a large surface-area-to-volume ratio and flow control, in inexpensive and portable devices. The microfluidic device in this work incorporated a dielectric barrier discharge generated in a continuous gas flow stream of a two-phase annular flow regime in the microchannels of the device. Methylene blue in solution was used to investigate plasma induced degradation of dissolved organic compounds within the microfluidic device. The relative degradation rates of methylene blue were influenced by the residence time of the sample solution in the discharge zone, type of gas applied, channel depth and flow rate. Increasing the residence time inside the plasma region led to higher levels of degradation. Oxygen was found to be the most effective gas, with the spectra obtained using Liquid Chromatography-Mass Spectroscopy indicating the most significant degradation. By reducing the channel depth from 100 to $50 \mu \mathrm{m}$, the best results were obtained, achieving a greater than $97 \%$ level of methylene blue degradation. The microfluidic system presented here demonstrates proof-of-concept that plasma technology can be utilised as an advanced oxidation process for water treatment, with the potential to eliminate water treatment consumables such as filters and disinfectants.
\end{abstract}

Keywords Atmospheric-plasma · Contamination · Dielectric barrier discharge · Microfluidic $\cdot$ Water treatment

\section{Abbreviations \\ AOP Advanced oxidation processes \\ DBD Dielectric barrier discharge \\ MB Methylene blue \\ MPR Microfluidic plasma reactor \\ PWT Plasma-based water treatment}

Kirsty J. Shaw

k.shaw@mmu.ac.uk

1 Faculty of Science and Engineering, Manchester Metropolitan University, Manchester, UK

2 Department of Chemistry and Biochemistry, University of Hull, Hull, UK 


\section{Introduction}

Conventional water treatment processes, such as filtration or coagulation followed by disinfection, fail to eliminate persistent contaminants from water sources effectively. Several studies linked failures in water treatment processes to contamination incidences of water sources [1-3]. Some of these incidents resulted in: the accumulation of dangerous levels of biological and chemical treatment resistant contaminants [4], pathogenic outbreaks [5] and the potential for adverse health effects [6]. In recent years, advanced oxidation processes (AOP), with plasma-based water treatment (PWT) in particular, have attracted considerable attention, since such methods have the potential to address the problems associated with conventional processes. PWT creates a wide spectrum of highly reactive oxidative species in the vicinity of the solution under treatment, in addition to driving electron-transfer reactions and producing UV radiation, there is also the possibility of thermal degradation [7]. The principle of PWT involves the oxidization or mineralization of contaminants to inorganic salts, water and carbon dioxide [7,8], without the addition of chemical agents. If the complete mineralisation of organic contaminants is achieved, no highly toxic or concentrated by-products would be present in the processed water; by-products which can be produced by conventional water treatment methods [9-11]. Although PWT is attractive, certain aspects, such as cost of operation and mass transfer limitations [12, 13], require further development to validate the performance of PWT compared to conventional water treatment technologies.

Several laboratory-scale plasma reactors have been designed and developed for organic contaminant degradation, which have adopted various types of plasma discharge, in water or at the water-gas interface. However, these have proven difficult to implement at the macro-scale [14]. PWT approaches have often been based on batch type reactors, which can achieve high levels of contaminant degradation, but at the cost of long residence times [15]. Ideally, any processing system for water treatment should be continuous flow, which would require a large plasma-liquid interfacial area for plasma species to be generated and diffuse into the liquid, allowing for treatment of varying quantities of effluent within a short space of time to meet supply and demand. Innovative continuous flow plasma reactors, such as falling water film reactors and reactors with radial flow, have been applied to increase plasma-liquid interfacial area to improve treatment efficiency [16, 17]. In these systems thin films of water flow along the inner walls of a vertical cylindrical electrode and come into contact with plasma. These reactors performed favourably in terms of high degradation capability, with high mass transfer of plasma species into the thin film of solution along the discharge. However, fluid control and even film distribution were difficult to achieve which can affect pollutant degradation efficiency. In addition, these systems are susceptible to electrode erosion processes.

Recently, by exploiting the advantages of miniaturisation, effective dielectric barrier discharge (DBD) systems within microfluidic platforms operated at atmospheric pressure have been presented and utilised for plasma characterisation and synthesis reactions [18-22], but these systems have yet to be applied to PWT. Plasma microfluidic devices have also been employed recently for plasma synthesis in dual phase plasma-liquid systems, in particular for gold nanoparticle synthesis [23], for synthesis reactions [24], and for controlled oxidative processes [25], with all three studies indicating the potential of dual phase plasma-liquid microfluidic systems for studies in plasma water treatment.

Microfluidics refers to devices and methods that allow the control of the spatial and temporal behaviour of fluids within dimensions less than a millimetre [26]. The high 
surface-area-to-volume ratios inherent to microfluidic systems used in a range of different applications present significant enhancement of the observed reaction rate compared to traditional, macroscale bulk reactors. Utilising a microfluidic approach can benefit PWT by maximising the plasma-liquid interfacial area, enhancing mass transfer and reducing transfer distance of reactive species in plasma to liquid in continuous flow. Although each device may only process a small volume at a time, larger volumes can be processed by operating multiple devices in parallel [27].

For these reasons, the present study evaluated a planar microfluidic plasma reactor (MPR) for water treatment, based on the degradation of methylene blue (MB) as a model micropollutant due to its stability and resistance to breakdown by conventional methods [28-30]. The MPR presented utilizes a DBD at atmospheric pressure, with the plasma generated in the gas stream of a continuous gas-liquid two-phase flow. The effect of residence time of the solution in the discharge zone, type of gas applied, barrier thickness and channel depth were evaluated.

\section{Materials and Methods}

\section{Plasma Reactor}

Microfluidic devices were fabricated using standard photolithography coupled with wet etching techniques [31] to produce the design shown in Fig. 1. Briefly, Schott B270 glass wafers coated in chrome and photoresist were placed under a mask and exposed to UV light. These wafers were developed and isotropically etched in a buffered hydrofluoric acid solution. Microchannels were etched on a $1 \mathrm{~mm}$ glass bottom plate, with depths of $100 \mu \mathrm{m}$ or $50 \mu \mathrm{m}$ and channel widths of $390 \mu \mathrm{m}$ and $330 \mu \mathrm{m}$ respectively. Both inlet and outlet holes [1/16" outer diameter (OD)] were drilled through a 1 or $3 \mathrm{~mm}$ thick glass top plate, aligned with the etched wafer and thermally bonded by heating in a furnace. Fluorinated ethylene propylene (FEP) tubing [1/16" OD $\times 0.030$ " inner diameter (ID)] was glued,

(a)

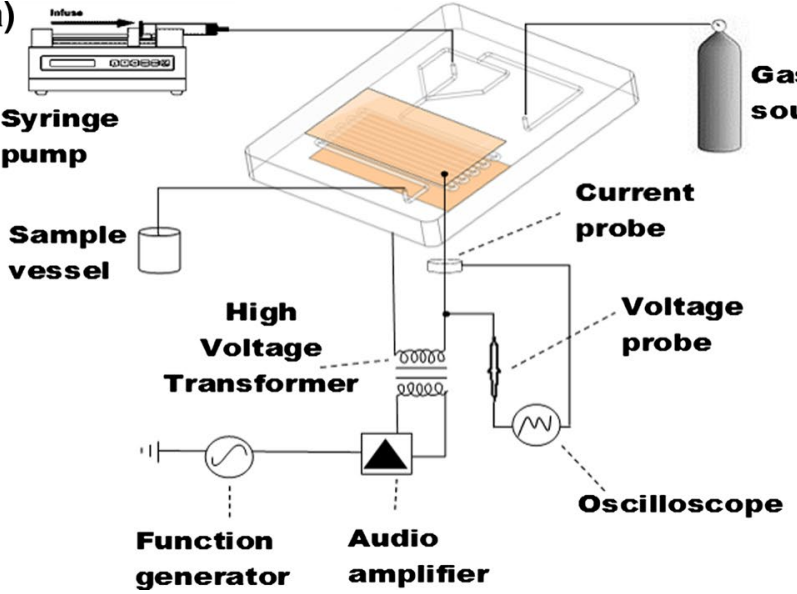

(b)

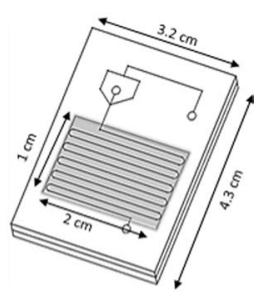

(c)

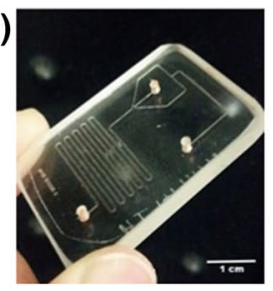

Fig. 1 a Schematic showing the experimental set-up of the microfluidic system; b Diagram of the microfluidic device design. $\mathbf{c}$ Photograph of the microfluidic device 
using Araldite two part epoxy adhesive (Huntsman Advance Materials, UK), to the glass microreactor. Copper tape (RS Components, UK) was used as high voltage and ground electrodes, size $20 \times 10 \mathrm{~mm}$ and $35 \mu \mathrm{m}$ thick. The microreactor device was fixed into a compressive case made of poly(methyl methacrylate) with windows to allow inlet tubing and electrical connections to be made. The electrodes were positioned on either side of the glass chip (grey area), on the serpentine microchannels, shown in Fig. 1b, encompassing a microchannel length of $210 \mathrm{~mm}$. Heat sinks were connected to both electrodes.

To investigate the effect of the working gas used for plasma formation in the microchannel; air, argon and oxygen were used. Gas-liquid two-phase annular flow was generated by parallel injection of compressed gas and liquid from separate inlets of the MPR. An in-house regulated gas line was employed to control the gas flow rate by changing the pressure of the gas at the inlet to 1 or 2 bar depending on the channel depth. The gas volume flow rate was approximately measured by attaching a Hamilton gas-tight syringe to the outlet. The gas volume collected from the outlet was measured as a function of time for device inlet pressures of 1 bar and a channel depth of $100 \mu \mathrm{m}$, and a device inlet pressure of 2 bar and a channel depth of $50 \mu \mathrm{m}$. This gave 4 and $8 \mathrm{~mL} / \mathrm{min}$ measured in devices with 50 and $100 \mu \mathrm{m}$ channel depth, respectively. A syringe pump (Cronus Sigma 2000C, SMI-LabHut Ltd., UK) was used to deliver the liquid solutions through a Hamilton gas-tight syringe, ranging from 30 to $150 \mu \mathrm{L} / \mathrm{min}$. Resulting flow regimes were observed in the downstream and serpentine regions of the chip using an inverted light microscope (Zeiss Primovert). Liquid film thickness was obtained from microscope images, with reference length scales used to calibrate these measurements.

A filamentary DBD regime was employed using copper electrodes aligned in parallel to the serpentine channel, with the glass of the microfluidic device acting as a dielectric barrier. The power supply consisted of a signal generator (TTi TG1000), audio amplifier (ProSound 1600) and custom-built high voltage transformer (Amethyst Designs). Current and voltage measurements were made with a Pearson 4100 current monitor and a Tektroniks 1000:1 voltage probe, recorded on a Tektronix DPO3014 digital oscilloscope. The average power applied to the microfluidic device was calculated [32] using Eq. (1):

$$
P_{t}=\int_{0}^{t} \sqrt{V_{t}^{2} \times I_{t}^{2}} d t
$$

where $\mathrm{P}_{\mathrm{t}}$ is the deposited power over one pulse duration in watts, $\mathrm{t}$ is the pulse duration in seconds, $\mathrm{V}$ is the applied voltage measured in volts and $\mathrm{I}$ is the input current measured in amperes.

\section{Analysis}

Analytical grade MB (Sigma Aldrich), at a concentration of $5 \mathrm{mg} / \mathrm{L}$ in deionised water (18.2 Mega Ohms per cm at room temperature) and kept at $\mathrm{pH} 7.4 \pm 0.5$ by $0.1 \mathrm{M}$ phosphate buffer, was used as a model sample for evaluation of the MPR. The concentration of MB was monitored, before and after plasma treatment, using a UV-vis spectrophotometer (Perkin Elmer Lambda 40) in the wavelength range of 200-800 nm. The concentration of MB was determined from the absorption maximum at $664 \mathrm{~nm}$, according to the Beer-Lambert law. The percentage of MB degradation due to plasma treatment was calculated using Eq. (2); 


$$
\text { Degradation }(\%)=\left(1-\frac{[\mathrm{MB}]}{\left[\mathrm{MB}_{0}\right]}\right) \times 100
$$

where $\left[\mathrm{MB}_{0}\right]$ is the initial concentration of the $\mathrm{MB}$ solution and $[\mathrm{MB}]$ is the final concentration after plasma treatment. The by-products formed with plasma treated MB solution were identified by means of a mass spectrometer coupled with an electrospray ionization source (ESI-MS) using an Agilent Technologies 6540 UHD Accurate-Mass Q-TOF LC/ MS.

The effects of temperature, $\mathrm{pH}$ and residence time in the absence of plasma were also tested, and were found to have no effect upon the degradation of MB solutions.

\section{Results and Discussion}

\section{Flow Characterisation}

Microscopic images were acquired showing the bottom view of the microfluidic device, with various flow regimes observed depending on the flow rates of gas and liquid in Fig. 2. The aqueous solution was injected into the microfluidic devices at flow rates between 30 and $150 \mu \mathrm{L} / \mathrm{min}$ and gas flow pressures at 1 and 2 bar in 100 and $50 \mu \mathrm{m}$ deep channels, respectively. In microfluidic devices, small variations in the flow rate conditions can lead to flow regime transitions, i.e. from stratified to annular flow and annular to plug flow patterns.

In our system, annular and plug flow regimes were observed, depending on the applied flow conditions. Annular flow was sustained at liquid flow rates, between 35 and $100 \mu \mathrm{L} / \mathrm{min}$, as shown in Fig. 2, while plug flow was observed at flow rates greater than $100 \mu \mathrm{L} / \mathrm{min}$ in $100 \mu \mathrm{m}$ deep channels. Liquid flow rates below $35 \mu \mathrm{L} / \mathrm{min}$ led to the eventual failure (leaking) of the syringe containing MB solution. This was because the liquid flow rate was insufficient to prevent gas from passing back through the fluidic network and into the syringe. Stratified flow was not generated at any of the flow conditions employed due to the attraction between the liquid column and the glass

$100 \mu \mathrm{m}$ channel depth

(1 bar gas pressure)

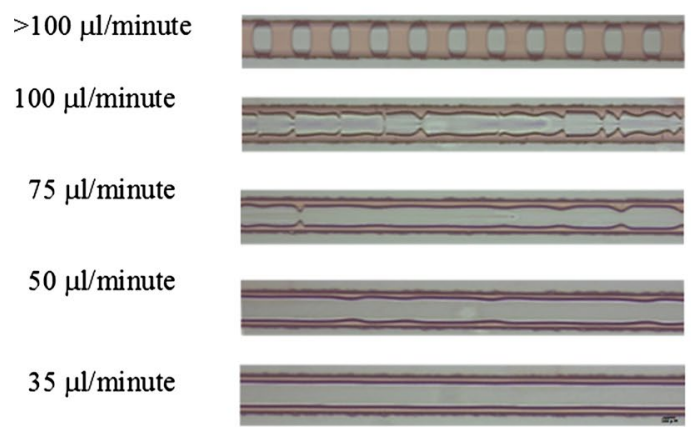

$50 \mu \mathrm{m}$ channel depth

( 2 bar gas pressure)
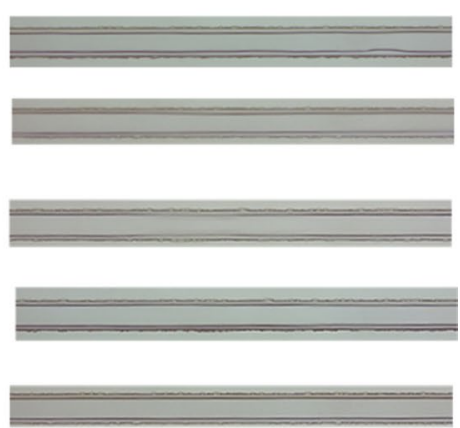

Fig. 2 Optical microscope images of the annular flow regime observed using various liquid flow rates, 100 and $50 \mu \mathrm{m}$ channel depth using 1 and 2 bar gas pressure of compressed air, respectively 
microchannel wall at both low and high flow rates, resulting in annular flow or plug flow. Prevention of transition to plug flow is important, since different flow regimes produce different flow velocities and mechanisms of diffusion and mixing, leading to an effective reduction in the plasma-liquid interfacial area which would influence the conversion of the solution treated by the device [33].

Annular flow was employed to test the plasma discharge within the microfluidic devices. With annular flow, the liquid is expelled from the centre of the microchannel and flows as a thin film along the channel wall while gas flows continuously in the middle, providing a continuous gas core for discharge. Liquid flow rates were set to $35-100 \mu \mathrm{L} / \mathrm{min}$ as minimum and maximum flow rates to avoid flow regime transition, or gas entering the sample syringe.

\section{Film Thickness and Residence Time}

Flow rates between 35 and $100 \mu \mathrm{L} / \mathrm{min}$ of liquid and $4-8 \mathrm{~mL} / \mathrm{min}$ of gas flow at $1-2$ bar gas pressure were investigated. These conditions produced a thin film of liquid on the walls of the microchannels, enabling control of two key parameters for PWT: liquid film thickness and residence time. In general, the microfluidic device operated with liquid films on the order of micrometres and residence times of seconds, compared to batch type plasma reactors reported in literature with residence times in the order of several minutes or hours and film thicknesses of several millimetres [12, 34-37]. The mean residence time of the solution in two-phase annular flow along the plasma discharge zone was estimated as the ratio of the inner volume of the reactor to the volumetric flow rate [38], ranging from 3 to $9 \mathrm{~s}$ and 1 to $5 \mathrm{~s}$ in $100 \mu \mathrm{m}$ and $50 \mu \mathrm{m}$ channel depths, respectively. Thin film characteristics were adjusted by varying the liquid flow rate, with the average film thickness found to increase as a function of liquid flow rate. Thin liquid films were achieved at low flow rates, with an estimated liquid film thickness, ranging from 60 to $100 \mu \mathrm{m}$ and 40 to $60 \mu \mathrm{m}$ in $100 \mu \mathrm{m}$ and $50 \mu \mathrm{m}$ channel depths, respectively. The stability of the liquid film observed in the microchannel was reduced at higher flow rates. Film thicknesses varied over time using flow rates greater than $35 \mu \mathrm{L} / \mathrm{min}$ in $100 \mu \mathrm{m}$ deep channels. Less surface deformation of the liquid film was observed in the $50 \mu \mathrm{m}$ channel depth compared to the $100 \mu \mathrm{m}$ channel depth using similar liquid flow rates. It is possible that surface deformation may have an effect on plasma stability, which is likely to be detrimental to effective treatment, but it is also likely to lead to greater mixing which should enhance treatment. The influence of these competing factors will require further investigation [39].

Residence time and the liquid film thickness are important parameters with significant effects on maximizing the plasma-liquid interfacial area and mass transfer of plasma induced species into the bulk of the liquid [15, 40]. Highly reactive species have inherently short lifetimes, hence they do not have much time to migrate into the liquid being treated and react as desired with the contaminants in the sample. Therefore it is advantageous to have as thin a layer of water as possible to maximise the effectiveness of the plasma treatment process. Increasing the residence time increases the amount of time available for treatment, which leads to higher levels of contaminant degradation. In our devices, the lowest liquid flow rate of $35 \mu \mathrm{L} / \mathrm{min}$ gave the thinnest films and the longest residence times. Residence times while using an annular flow 
regime can be increased further by extending the discharge zone where plasma and liquid interact.

\section{Plasma Characterisation}

Characteristic current-voltage (I-V) sinusoidal waveforms of a DBD generated in the microfluidic device are shown in Fig. 3. The current waveform, with numerous narrow peaks is typical for DBD, where discharge is generated within a gas filled cavity in the form of filamentary streamers. In this case, each narrow peak represents plasma filaments passing across the channel of the MPR. The use of a dielectric barrier along the discharge path prevents the glow discharge transforming to an arc or spark [41] and this allows the discharge to be sustained at low input power. The electrode voltage from the AC power supply was controlled at a peak-to-peak applied voltage of approximately $10 \mathrm{kV}$ and the frequency was set to $17 \mathrm{kHz}$. In general, for the applied voltage used, the average power consumption was found to be $\mathrm{P}=13.0 \pm 0.7 \mathrm{~W}$ [41]. The rate of plasma generation was predicted to be constant based on a consistent applied AC voltage to the plasma reactor at various liquid flow rates.

It was assumed that the plasma generation in the microfluidic devices was confined to the gas column within the microchannel. Figure 2 shows the gas space decreasing as a function of increasing liquid flow rate. At higher flow rates, film thickness and surface deformation increased, which may leave less space for plasma generation and affect the gas volume for excitation and ionization [42]. Numerous studies have found treatment efficiency by plasma discharges to be influenced by the liquid to gas volume ratio [43]. So far, however, limited studies have been performed with a similar reactor configuration and examined plasma generation in a two-phase annular flow regime. At present, our electrodes are not made of transparent materials and it is not known if the plasma alters the annular flow regime in our devices. However, it is assumed that the plasma discharge does not have any significant effect on the flow regime inside the devices.

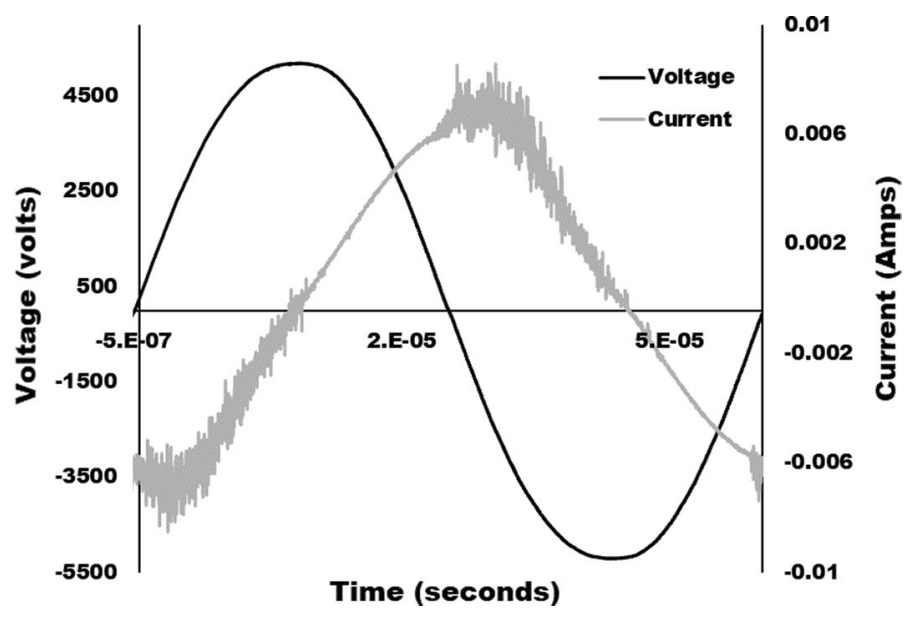

Fig. 3 Applied voltage and discharge current at an inlet air pressure of 1 bar, $100 \mu \mathrm{L} / \mathrm{min}$ liquid flow rate, $2 \mathrm{~mm}$ barrier thickness and a channel depth of $100 \mu \mathrm{m}$ 
Under a given power input supplied into the device, the rate of generated plasma species was assumed to reach a pseudo-steady state.

\section{Evaluation of Degradation Potential}

\section{Effect of Working Gas}

The MPR was operated using air, argon and oxygen as working gases. MB degradation was more evident when oxygen was used as the working gas (Fig. 4). By increasing the residence time of the MB solution in the plasma discharge zone, exposure of the MB solution to plasma increased and higher MB degradation was achieved. Kinetic behaviour of the degradation process was obtained by fitting the data to a pseudo-first order kinetic model (Eq. 4) based on the relationship between the degradation efficiency $(\eta)$, rate constant $(k)$ and estimated residence time (t) $[42,44]$.

$$
\eta=1-\mathrm{e}^{-\mathrm{kt}}
$$

The rate constant obtained by the best fit of Eq. (4) to the data in Fig. 4 is $0.088 \mathrm{~s}^{-1}, 0.11 \mathrm{~s}^{-1}$ and $0.13 \mathrm{~s}^{-1}$ for air, argon and oxygen respectively. This model was used to show that using the microfluidic device allows high degradation efficacy to be achieved, with residence times in the order of seconds rather than the minutes or hours that have been reported in numerous studies [34-37, 45]. The results show that maximising residence time leads to enhanced degradation. However, the rate of increase in degradation (\%) starts to tail off at higher residence times, due to the first order kinetics of the degradation process. In addition to residence time, degradation (\%) can be enhanced depending on the working gas, as shown in Fig. 4.

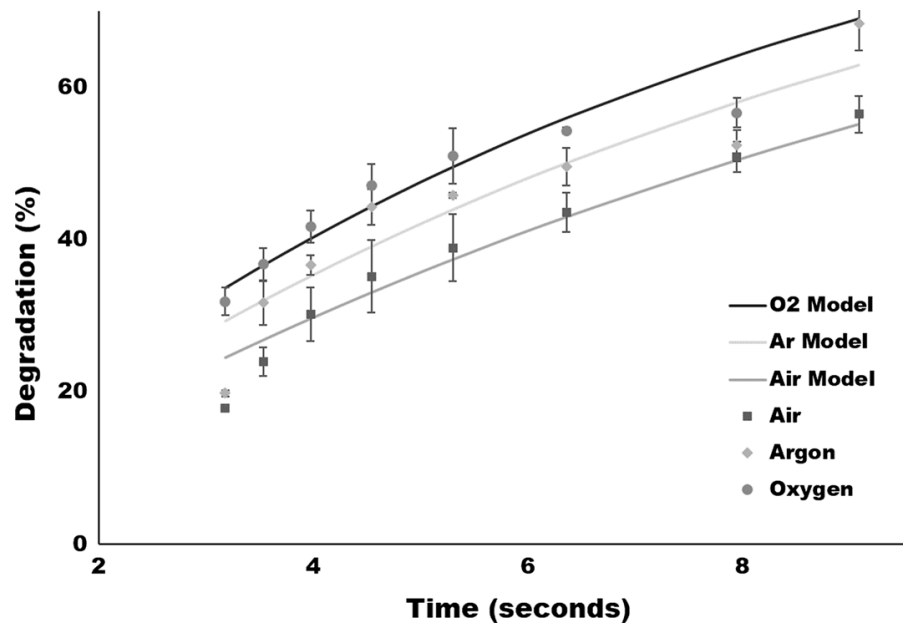

Fig. 4 Degradation efficiencies, as a function of residence time, with different working gases at 1 bar, applied voltage at $10 \mathrm{kV}$ and frequency of $17 \mathrm{kHz}$. Air $\left(\mathrm{k}=0.088 \mathrm{~s}^{-1}, \mathrm{R}^{2}=0.9952\right)$, $\operatorname{argon}\left(\mathrm{k}=0.11 \mathrm{~s}^{-1}\right.$, $\left.\mathrm{R}^{2}=0.9927\right)$ and oxygen $\left(\mathrm{k}=0.13 \mathrm{~s}^{-1}, \mathrm{R}^{2}=0.9898\right)$. Channel depth of $100 \mu \mathrm{m}$. Error bars represent standard error $(\mathrm{n}=3)$. Statistical significance, $P<0.05$ 
High-energy electrons $\left(\mathrm{e}^{*}\right)$ generated in the plasma produce reactive free radicals by reactions at the plasma-liquid interface, generating species such as (Eq. 4): [46-48].

$$
\mathrm{H}_{2} \mathrm{O}+\mathrm{e}^{*} \rightarrow \mathrm{OH}+\mathrm{H}^{\cdot}+\mathrm{e}
$$

However, nitrogen containing species generated in plasma are known to scavenge reactive species such as ozone and hydroxyl radicals (Eqs. 5-6) [49, 50]:

$$
\begin{gathered}
\mathrm{O}_{3}+\mathrm{NO}_{2}^{-} \rightarrow \mathrm{O}_{2}+\mathrm{NO}_{3}^{-} \\
\mathrm{OH}+\mathrm{NO}_{2}^{-} \rightarrow \mathrm{OH}^{-}+\mathrm{NO}_{2}
\end{gathered}
$$

The higher degradation of $\mathrm{MB}$ observed with argon and oxygen as the working gases compared to air can be attributed to the absence of scavenging nitrogen species [51, 52]. Argon mainly relies on electron impact ionization of water molecules to produce hydroxyl radicals and hydrogen peroxide. With plasma discharges conducted in oxygen, greater amounts of reactive oxygen species are produced, in addition to hydroxyl radicals. [53, 54].

\section{Effect of Channel Depth}

Figure 5 shows the effect of reducing the channel depth of the microfluidic device on the degradation of MB, using air as the working gas. The use of a shallower channel depth reduced the residence time of the liquid in the microchannel. Despite the shorter residence time, the results show significant improvement in MB degradation, with a maximum of $97 \%$ achieved, using a shallower channel depth and a liquid flow rate of $35 \mu \mathrm{L} / \mathrm{min}$. The maximum residence time calculated in the $50 \mu \mathrm{m}$ deep channel device was $4.543 \mathrm{~s}$.

The discharge gap distance, i.e. the channel depth of the microfluidic device, is important in terms of breakdown voltage. With a small gap distance, lower breakdown voltage and higher discharge current is expected [55]. Hence decreasing the discharge gap from

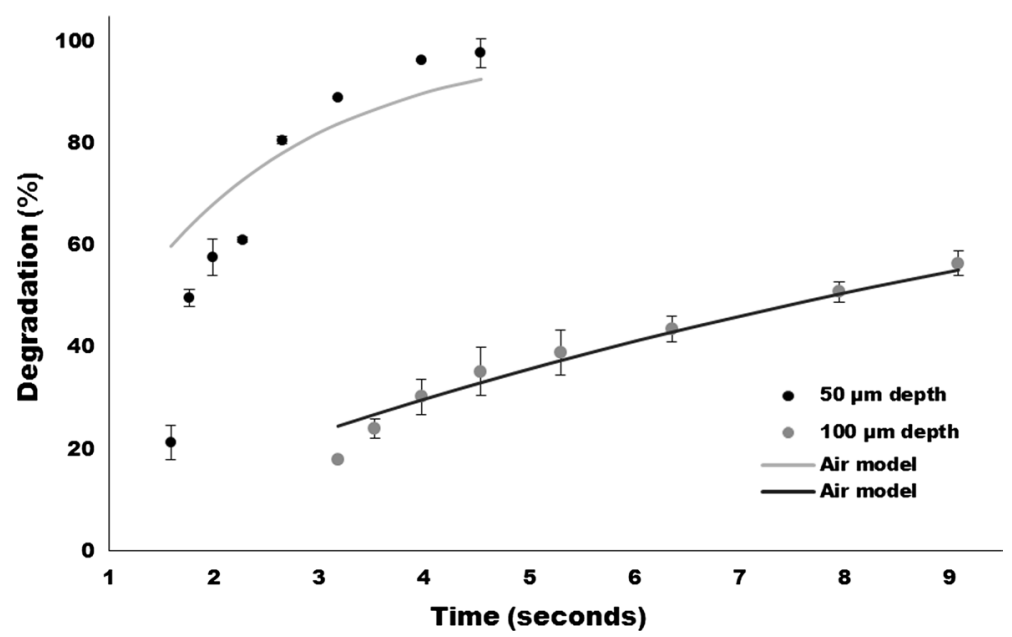

Fig. 5 Degradation efficiency, as a function of residence time, at different channel depths of 50 and $100 \mu \mathrm{m}$, air as the feed gas at 4 and $8 \mathrm{~mL} / \mathrm{min}$ respectively, applied voltage at $10 \mathrm{kV}$ and frequency of $17 \mathrm{kHz}$. $100 \mu \mathrm{m}\left(\mathrm{k}=0.088 \mathrm{~s}^{-1}, \mathrm{R}^{2}=0.9952\right)$ and $50 \mu \mathrm{m}$ channel depths $\left(\mathrm{k}=0.573 \mathrm{~s}^{-1}, \mathrm{R}^{2}=0.8938\right)$. Error bars represent standard error $(\mathrm{n}=3)$. Statistical significance, $P<0.05$ 
100 to $50 \mu \mathrm{m}$, increases the power density in the discharge zone [56]. As a result, a more reactive environment is expected and consequently the collision probability is increased between the reactive species in the plasma and the liquid in the channels. In addition, using a shallower channel reduced the liquid film thickness compared to the deeper channels which would have improved the utilisation of short lived radicals for MB degradation in solution. Finally, the increase in pressure from 1 to 2 bar leads to an overall increase in the density of gas in the discharge regions, and potentially an increase in the concentration of active plasma species.

\section{Effect of Barrier Thickness}

Figure 6 shows MB degradation for different barrier thicknesses. Barrier thicknesses of the microfluidic devices were modified by using different thickness top plates ( 1 or $3 \mathrm{~mm}$ ) whilst maintaining a bottom plate thickness of $1 \mathrm{~mm}$. The results show that decreasing the barrier thickness improves MB degradation.

As the barrier increases in thickness, the capacitance due to the barrier decreases resulting in a greater voltage drop across the barrier, and less voltage applied across the gas gap. This results in a reduced power applied to the plasma region, reducing the electron density and chance of collisions in the gas space, and leading to lower concentration of ions and excited atoms formed in the plasma [57-60]. It was observed that the MB degradation using the microfluidic device was greatest using an overall $2 \mathrm{~mm}$ barrier thickness, with $50 \mu \mathrm{m}$ channel depth and $35 \mu \mathrm{L} / \mathrm{min}$ as the liquid flow rate.

\section{Degradation Mechanisms}

To give a qualitative indication of the types of degradation products produced by plasmas in different working gases, mass spectra were obtained for untreated and plasma treated MB samples that were processed through the MPR. Untreated MB showed a prominent peak at $284 \mathrm{~m} / \mathrm{z}$ consistent with its molecular structure (Fig. 7, top panel). After plasma treatment, differences in the relative intensity and number of fragments of MB were observed for each working gas used for plasma treatment. Routes of MB degradation and intermediates generated by plasma using different working gases as reported by several studies in literature were compared to our results, as shown in Fig. 7 (lower panels) [61-63]. The spectra obtained using oxygen as the working gas produced the greatest number of degradation products. Although concentrations cannot be determined from these measurements, and so it is not possible to determine the extent of complete mineralisation, it is clear that a significant number of degradation fragments are present in the samples following plasma treatment. $\mathrm{MB}$ is a relatively large molecule that requires many steps for its complete mineralisation to $\mathrm{CO}_{2}, \mathrm{H}_{2} \mathrm{O}$ and inorganic salts. It is expected that a longer treatment time by increasing the residence time of $\mathrm{MB}$ solution in the plasma discharge zone and further optimisation of the microfluidic device system will lead to enhanced mineralisation.

\section{Conclusions}

A microfluidic atmospheric-pressure plasma reactor proved to be an effective tool for the degradation of $\mathrm{MB}$ in solution in a continuous flow regime. The relative reactivity was affirmed by analysing the treated solution collected from the outlet. The degradation 

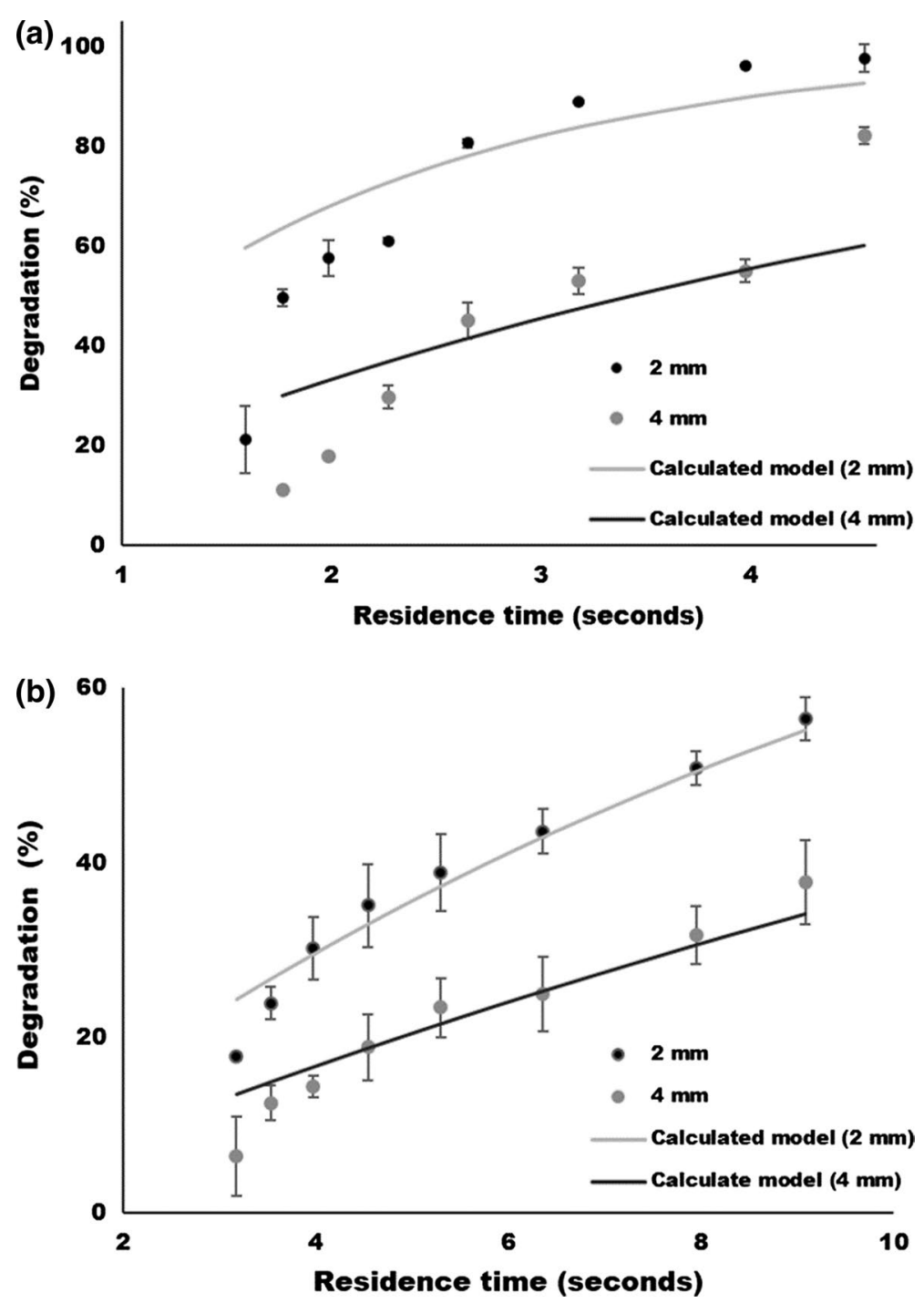

Fig. 6 Effect of barrier thickness on MB degradation in constant plasma discharge with an applied voltage of $\sim 10 \mathrm{kV}$, frequency of $17 \mathrm{kHz}$, gas flow pressure of 1-2 bar and channel depth of $50 \mu \mathrm{m}(\mathbf{a})$ and $100 \mu \mathrm{m}$ (b). Total barrier thicknesses of $2 \pm 0.1$ and $4 \pm 0.1 \mathrm{~mm}$ were used in this study

rates of the MB solution varied as a function of liquid flow rate, working gas, channel depth and barrier thickness. Oxygen was found to be the most effective working gas. Degradation was enhanced by using: lower liquid flow rates, thinner dielectric barriers and shallower channel depths. With air as the carrier gas, a degradation level of $97 \%$ was achieved at a liquid flow rate of $35 \mu \mathrm{L} / \mathrm{min}$, a barrier thickness of $2 \mathrm{~mm}$ and a channel depth of $50 \mu \mathrm{m}$. Miniaturized plasma-based reactors have a promising future for application to water treatment and chemical synthesis. Multiple MPR devices can be operated in an array to produce an effective continuous flow system for the removal of 

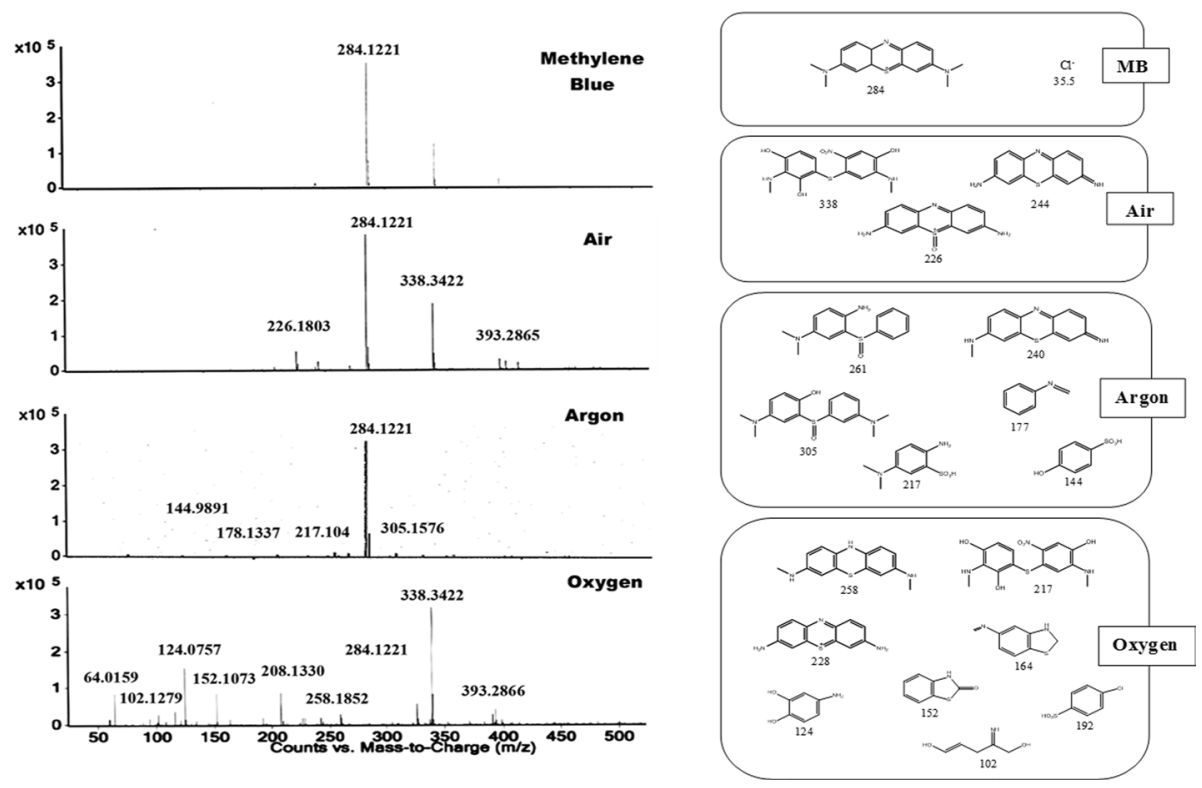

Fig. 7 Comparison of mass spectra of plasma treated and untreated methylene blue. Various ions as detected by the MS. Molecular ion $\left(\mathrm{MB}^{+}\right)=\mathrm{m} / \mathrm{z} 284.1221$. Results taken with the different working gases at 1 bar inlet pressure, applied voltage at $10 \mathrm{kV}$, frequency of $17 \mathrm{kHz}$, liquid flow rate of $35 \mu \mathrm{L} / \mathrm{min}$ and channel depth of $100 \mu \mathrm{m}$

persistent organic molecules from water resources. Such a system can be highly portable and operate without the need for reagents or consumables, to provide high quality drinking water or process water for critical applications, for example, in neonatal care in hospitals.

Acknowledgements LP received a Faculty of Science and Engineering Ph.D. studentship funded by Manchester Metropolitan University.

\section{Compliance with Ethical Standards}

Conflict of interest The authors declare that they have no conflict of interest.

Open Access This article is distributed under the terms of the Creative Commons Attribution 4.0 International License (http://creativecommons.org/licenses/by/4.0/), which permits unrestricted use, distribution, and reproduction in any medium, provided you give appropriate credit to the original author(s) and the source, provide a link to the Creative Commons license, and indicate if changes were made.

\section{References}

1. Naidoo S, Olaniran AO (2013) Treated wastewater effluent as a source of microbial pollution of surface water resources. Int J Environ Res Public Health 11(1):249-270

2. Piri I, Homayoonnezhad I, Amirian P (2010) Investigation on optimization of conventional drinking water treatment plant. In: 2010 2nd international conference on chemical, biological and environmental engineering (ICBEE). IEEE, pp 304-310 
3. Shi H, Cheng X, Wu Q, Mu R, Yinfa M (2012) Assessment and removal of emerging water contaminants. J Environ Anal Toxicol S2:003

4. Rajasulochana P, Preethy V (2016) Comparison on efficiency of various techniques in treatment of waste and sewage water-a comprehensive review. Resour Eff Technol 2(4):175-184

5. Moreira N, Bondelind M (2017) Safe drinking water and waterborne outbreaks. J Water Health 15(1):83-96

6. Etchepare R, van der Hoek JP (2015) Health risk assessment of organic micropollutants in greywater for potable reuse. Water Res 72:186-198

7. Jiang B, Zheng J, Qiu S, Wu M, Zhang Q, Yan Z, Xue Q (2014) Review on electrical discharge plasma technology for wastewater remediation. Chem Eng J 236:348-368

8. Malik MA, Ghaffar A, Malik SA (2001) Water purification by electrical discharges. Plasma Sour Sci Technol 10(1):82

9. Lin SD, Green CD (1987) Wastes from water treatment plants: literature review, results of an Illinois survey, and effects of alum sludge application to cropland. Illinois State Water Survey, Illinois

10. Ippolito J, Barbarick K, Elliott H (2011) Drinking water treatment residuals: a review of recent uses. J Environ Qual 40(1):1-12

11. Matsui Y, Takeuchi N, Sasaki K, Hayashi R, Yasuoka K (2011) Experimental and theoretical study of acetic-acid decomposition by a pulsed dielectric-barrier plasma in a gas-liquid two-phase flow. Plasma Sour Sci Technol 20(3):034015

12. Vanraes P (2016) Electrical discharge as water treatment technology for micropollutant decomposition. Ghent University, Ghent

13. Sirés I, Brillas E (2012) Remediation of water pollution caused by pharmaceutical residues based on electrochemical separation and degradation technologies: a review. Environ Int 40:212-229

14. Foster JE (2017) Plasma-based water purification: challenges and prospects for the future. Phys Plasmas 24(5):055501

15. Malik MA (2010) Water purification by plasmas: which reactors are most energy efficient? Plasma Chem Plasma Process 30(1):21-31

16. Dojčinović BP, Obradović BM, Kuraica MM, Pergal MV, Dolić SD, Inđić DR, Tosti TB, Manojlović DD (2016) Application of non-thermal plasma reactor for degradation and detoxification of high concentrations of dye Reactive Black 5 in water. J Serb Chem Soc 81(7):829-845

17. Wang B, Xu M, Chi C, Wang C, Meng D (2017) Degradation of methyl orange using dielectric barrier discharge water falling film reactor. J Adv Oxid Technol 20(2):20170021

18. Ishii C, Stauss S, Kuribara K, Urabe K, Sasaki T, Terashima K (2015) Atmospheric pressure synthesis of diamondoids by plasmas generated inside a microfluidic reactor. Diam Relat Mater 59:40-46

19. Yamanishi Y, Sameshima S, Kuriki H, Sakuma S, Arai F (2013) Transportation of mono-dispersed micro-plasma bubble in microfluidic chip under atmospheric pressure. In: The 17th international conference on solid-state sensors, actuators and microsystems Transducers and Eurosensors XXVII. IEEE, pp 1795-1798

20. Tatoulian M, Ognier S, Zhang M (2015) Diphasic gas/liquid plasma reactor. PCT/EP2016/080475

21. Schelcher G, Guyon C, Ognier S, Cavadias S, Martinez E, Taniga V, Malaquin L, Tabeling P, Tatoulian M (2014) Cyclic olefin copolymer plasma millireactors. Lab Chip 14(16):3037-3042

22. Olabanji OT, Bradley JW (2011) The development and analysis of plasma microfluidic devices. Surf Coat Technol 205:S516-S519

23. Li D-E, Lin C-H (2018) Microfluidic chip for droplet-based AuNP synthesis with dielectric barrier discharge plasma and on-chip mercury ion detection. RSC Adv 8(29):16139-16145

24. Zhang M, Ognier S, Touati N, Hauner I, Guyon C, Binet L, Tatoulian M (2018) A plasma/liquid microreactor for radical reaction chemistry: an experimental and numerical investigation by EPR spin trapping. Plasma Process Polym 15:1700188

25. Wengler J, Ognier S, Zhang M, Levernier E, Guyon C, Ollivier C, Fensterbank L, Tatoulian M (2018) Microfluidic chips for plasma flow chemistry: application to controlled oxidative processes. React Chem Eng 3(6):930-941

26. Luo D, Duan Y (2012) Microplasmas for analytical applications of lab-on-a-chip. TrAC Trends Anal Chem 39:254-266

27. Iles A (2009) Microsystems for the enablement of nanotechnologies. Nanotechnol Percept 5(2):121-133

28. Yagub MT, Sen TK, Afroze S, Ang HM (2014) Dye and its removal from aqueous solution by adsorption: a review. Adv Coll Interface Sci 209:172-184

29. Nawaz MS, Ahsan M (2014) Comparison of physico-chemical, advanced oxidation and biological techniques for the textile wastewater treatment. Alex Eng J 53(3):717-722 
30. Gupta VK, Ali I, Saleh TA, Nayak A, Agarwal S (2012) Chemical treatment technologies for wastewater recycling - an overview. RSC Adv 2(16):6380-6388

31. Scheuble N, Iles A, Wootton RC, Windhab EJ, Fischer P, Elvira KS (2017) Microfluidic technique for the simultaneous quantification of emulsion instabilities and lipid digestion kinetics. Anal Chem 89(17):9116-9123

32. Archambault-Caron M, Gagnon H, Nisol B, Piyakis K, Wertheimer MR (2015) Precise energy and temperature measurements in dielectric barrier discharges at atmospheric pressure. Plasma Sour Sci Technol 24(4):045004

33. Gobert SR, Kuhn S, Braeken L, Thomassen LC (2017) Characterization of milli-and microflow reactors: mixing efficiency and residence time distribution. Org Process Res Dev 21(4):531-542

34. Dojčinović BP, Roglić GM, Obradović BM, Kuraica MM, Kostić MM, Nešić J, Manojlović DD (2011) Decolorization of reactive textile dyes using water falling film dielectric barrier discharge. J Hazard Mater 192(2):763-771

35. Aziz KHH, Mahyar A, Miessner H, Mueller S, Kalass D, Moeller D, Khorshid I, Rashid MAM (2018) Application of a planar falling film reactor for decomposition and mineralization of methylene blue in the aqueous media via ozonation, Fenton, photocatalysis and non-thermal plasma: a comparative study. Process Saf Environ Prot 113:319-329

36. Krupež J, Kovačević VV, Jović M, Roglić GM, Natić MM, Kuraica MM, Obradović BM, Dojčinović BP (2018) Degradation of nicotine in water solutions using a water falling film DBD plasma reactor: direct and indirect treatment. J Phys D Appl Phys 51(17):174003

37. Jones DB, Raston CL (2017) Improving oxidation efficiency through plasma coupled thin film processing. RSC Adv 7(74):47111-47115

38. Fogler HS (1999) Elements of chemical reaction engineering. 1999

39. Bruggeman P, Graham L, Degroote J, Vierendeels J, Leys C (2007) Water surface deformation in strong electrical fields and its influence on electrical breakdown in a metal pin-water electrode system. J Phys D Appl Phys 40(16):4779

40. Foster JE, Mujovic S, Groele J, Blankson IM (2018) Towards high throughput plasma based water purifiers: design considerations and the pathway towards practical application. J Phys D Appl Phys 51(29):293001

41. Brandenburg R (2017) Dielectric barrier discharges: progress on plasma sources and on the understanding of regimes and single filaments. Plasma Sour Sci Technol 26(5):053001

42. Thagard SM, Stratton GR, Dai F, Bellona CL, Holsen TM, Bohl DG, Paek E, Dickenson ER (2016) Plasma-based water treatment: development of a general mechanistic model to estimate the treatability of different types of contaminants. J Phys D Appl Phys 50(1):014003

43. Vanraes P, Bogaerts A (2018) Plasma physics of liquids-a focused review. Appl Phys Rev 5(3):031103

44. Yin H, Xiong L, Jiang B, Zheng J, Xue Q (2014) Non-thermal plasma technology for methylene blue decolorization in continuous and circulating system: kinetic model and reactor performance. J Adv Oxid Technol 17(2):265-280

45. Attri P, Tochikubo F, Park JH, Choi EH, Koga K, Shiratani M (2018) Impact of gamma rays and DBD plasma treatments on wastewater treatment. Sci Rep 8(1):2926

46. Samukawa S, Hori M, Rauf S, Tachibana K, Bruggeman P, Kroesen G, Whitehead JC, Murphy AB, Gutsol AF, Starikovskaia S (2012) The 2012 plasma roadmap. J Phys D Appl Phys 45(25):253001

47. Locke BR, Shih K-Y (2011) Review of the methods to form hydrogen peroxide in electrical discharge plasma with liquid water. Plasma Sour Sci Technol 20(3):034006

48. Ruma Hosseini S, Yoshihara K, Akiyama M, Sakugawa T, Lukeš P, Akiyama H (2014) Properties of water surface discharge at different pulse repetition rates. J Appl Phys 116(12):123304

49. Nikitenko S, Venault L, Moisy P (2004) Scavenging of OH radicals produced from $\mathrm{H} 2 \mathrm{O}$ sonolysis with nitrate ions. Ultrason Sonochem 11(3-4):139-142

50. Son H-S, Ahammad A, Rahman M, Noh K-M, Lee J-J (2011) Effect of nitrite and nitrate as the source of $\mathrm{OH}$ Radical in the $\mathrm{O} 3 / \mathrm{UV}$ process with or without benzene. Bull Korean Chem Soc 32(spc8):3039-3044

51. Feng X, Yan B, Yang Q, Jin Y, Cheng Y (2016) Gas-liquid dielectric barrier discharge falling film reactor for the decoloration of dyeing water. J Chem Technol Biotechnol 91(2):431-438

52. Kovačević VV, Dojčinović BP, Jović M, Roglić GM, Obradović BM, Kuraica MM (2017) Measurement of reactive species generated by dielectric barrier discharge in direct contact with water in different atmospheres. J Phys D Appl Phys 50(15):155205

53. Bruggeman P, Kushner MJ, Locke BR, Gardeniers JG, Graham W, Graves DB, Hofman-Caris R, Maric D, Reid JP, Ceriani E (2016) Plasma-liquid interactions: a review and roadmap. Plasma Sour Sci Technol 25(5):053002 
54. Sano N, Kawashima T, Fujikawa J, Fujimoto T, Kitai T, Kanki T, Toyoda A (2002) Decomposition of organic compounds in water by direct contact of gas corona discharge: influence of discharge conditions. Ind Eng Chem Res 41(24):5906-5911

55. Yoon S-Y, Jeon H, Yi C, Park S, Ryu S, Kim SB (2018) Mutual interaction between plasma characteristics and liquid properties in AC-driven Pin-to-liquid discharge. Sci Rep 8(1):12037

56. Ohtsu Y, Fujita $\mathrm{H}$ (2004) Influences of gap distance on plasma characteristics in narrow gap capacitively coupled radio-frequency discharge. Jpn J Appl Phys 43(2R):795

57. Yang D-Z, Wang W-C, Zhang S, Tang K, Z-j Liu, Wang S (2013) Multiple current peaks in room-temperature atmospheric pressure homogenous dielectric barrier discharge plasma excited by high-voltage tunable nanosecond pulse in air. Appl Phys Lett 102(19):194102

58. Li M, Li C, Zhan H, Xu J, Wang X (2008) Effect of surface charge trapping on dielectric barrier discharge. Appl Phys Lett 92(3):031503

59. Tao S, Kaihua L, Cheng Z, Ping Y, Shichang Z, Ruzheng P (2008) Experimental study on repetitive unipolar nanosecond-pulse dielectric barrier discharge in air at atmospheric pressure. J Phys D Appl Phys 41(21):215203

60. Liu Z, Wang W, Zhang S, Yang D, Jia L, Dai L (2012) Optical study of a diffuse bipolar nanosecond pulsed dielectric barrier discharge with different dielectric thicknesses in air. Eur Phys J D 66(12):319

61. Wang B, Dong B, Xu M, Chi C, Wang C (2017) Degradation of methylene blue using double-chamber dielectric barrier discharge reactor under different carrier gases. Chem Eng Sci 168:90-100

62. Shirafuji T, Ishida Y, Nomura A, Hayashi Y, Goto M (2017) Reaction mechanisms of methylene-blue degradation in three-dimensionally integrated micro-solution plasma. Jpn J Appl Phys 56(6S2):06HF02

63. Bansode AS, More SE, Siddiqui EA, Satpute S, Ahmad A, Bhoraskar SV, Mathe VL (2017) Effective degradation of organic water pollutants by atmospheric non-thermal plasma torch and analysis of degradation process. Chemosphere 167:396-405

Publisher's Note Springer Nature remains neutral with regard to jurisdictional claims in published maps and institutional affiliations. 